\title{
Concept of Creation of E-Platforms as Part of Support for Small Innovational Business
}

\author{
Svetlana S. Morkovina1 \\ Marianna S. Santalova ${ }^{2}$ \\ Michael V. Drapalyuk ${ }^{3}$ \\ Ekaterina A. Panyavina ${ }^{4}$
}

\begin{abstract}
1 Voronezh State Academy of Forestry and Technologies, Voronezh, Russian Federation
2 Russian Economic University named after G. V. Plekhanov, Voronezh branch, Voronezh, Russian Federation

${ }^{3}$ Voronezh State Academy of Forestry and Technologies, Voronezh, Russian Federation

${ }^{4}$ Voronezh State Academy of Forestry and Technologies, Voronezh, Russian Federation
\end{abstract}

\section{Doi:10.5901/mjss.2015.v6n6p57}

\section{Abstract}

The article substantiates the necessity of creating effective elements of innovational infrastructure - electronic Internet resources, including formation of main provisions, organizational principles, and system of measures for increasing accessibility of capital for beginning entrepreneurs, growth of investment activity of organizations, and inflow of investments into the spheres of business activities. The article studies the principles of creation of E-resource - investment and innovational E-platform for cooperation of small innovational business and investors; principle of demonopolization of investors; principle of startups' competition; principle of cooperation; principle of free choice of terms of provision of investment service and its forms for startups; principles of reliability and guarantees for startups for protecting their interests; principle of publicity allows members of platform to solve the issue of partners selection; principle of distinction of functions of experts and investors; principle of competence and professionalism of experts. Algorithms of creation, functioning, and management of E-platform are formed, and necessity for material, labor, and financial resources is substantiated. It is proved that effectiveness of creation of $E$ platform directly depends on the level of cooperation of startups and investors, organizational and legal form of creation of $E$ platform and its provision with material, labor, and financial resources, complex of marketing, and measures for popularization of E-resource. The forecasts of functioning of E-resource are built which reflect the income of electronic Internet platform, expected due to present demand for similar services in the market of investments and innovations.

Keywords: small innovational business, support, startup, investment and innovational E-platform.

\section{Introduction}

The global experience shows that subjects of small business exceed large and medium business as to the quantity of novelties and innovations, level of commercialization of new products, patenting index, etc. [Shevchenko, 2010; Yulenkova, 2008; Morkovina, 2014].

The gap between Russia and developed countries in main indicators of development of small business on the whole and small innovational business in particular is substantial. The quantity of small and medium enterprises in Russia is by 23 times smaller than in the US, by 7.7 times smaller than in Japan, and by 2.5 times smaller than in France [Odarenko, 2011] The number of the employed in the sector of small and medium business in Russia is 3 times smaller than the same indicator not only of developed countries but of some countries with transitional economy. The share of small innovational enterprises in the total number of small enterprises of Russia constitutes $0.8 \%$. Small innovational enterprises' share of investments into main capital and revenue is $0.3 \%$, and share of employed in the sphere of small business $-0.6 \%$ [Goncharova, 2009]. To compare: the share of small innovational enterprises in the total number of small enterprises constitutes: in France - 38\%, in Great Britain - 24\%, in Norway - 49\%, in Germany - 62\%, and in Ireland - 75\%. [Nesterenko, 2006.]

It is impossible to overcome this gap without accelerated development of all links of infrastructure of support for small innovational business, including institutes of investments and venture financing [Popkova, 2014].

For the purpose of supporting entrepreneurs, a large number of informational resources and educational platforms were created over the recent years; they help beginning businessmen to learn the basics of company creation, tools that 
they will need for that, and events where they can gather their team [Morkovina, 2014]. Many of them are free. Except for informing, help to businessmen also includes various grant systems (which are vitally important for knowledge-intensive directions, like biotechnologies and nanotechnologies). Reduction of informational barrier led to quick popularization of startups.

At present, there can be observed a rising popularity of infrastructural platforms for support for starting businesses in Russia - from simple IT solutions to support for industrial startups [Panyavina, 2014]. Under the conditions of competition between companies in the Internet market and rivalry over venture capital, innovation and creativity are the factors of conquering and preserving leading positions. There is exponential growth of startup companies in the Internet.

At the same time, there is certain number of problems, peculiar for the Russian market, which should not be neglected by the state structures; they are related to determining the legal form of creation of the Internet platforms, evaluation of need for resources, and effectiveness of functioning [Bezrukova T.L., 2015]. Quick change of the Russian and foreign Internet economy, formation of standards of work and adaptation of businessmen to the conditions of development of business in the Internet, and creation of attractive innovational and venture environment predetermined the necessity for formation of the concept of creation of E-platforms in the framework of support for small innovational business.

\section{Materials and Methods}

The research also includes short analysis of general statistics of creation and development of small innovational enterprises-startups, presents factors which restrain development of subjects of small innovational business, and analyzes programs of support for startups which are implemented at the level of the Russian Federation and separate regions.

The research uses the complex approach to the study of potential of small innovational business by the example of Voronezh Oblast, when the sources of information on startups are federal and regional informational resources, data of monitoring of printed and electronic business and specialized materials, analytical reviews, and materials of web-sites for the period of 2010-2015. The sources of information are specialized resources from the Internet (web-sites of the Russian and local authorities, universities, business angels, venture funds, departments of administrations and governments of regions, investment funds, scientific and technical centers, enterprises and organizations which use innovations, and electronic mass media).

In order to determine top-priority forms of support for small innovational business, there were prepared and sent (including via e-mail) informational letters with questionnaires and offer to participate in the survey (to 250 addresses). Certain part of respondents - 11 (or $4 \%$ of the total quantity) refused to take part in the survey, or provided blank forms.

During the survey, the methods of comparison, contrast, and polling were used in the part of:

- polling of small innovational enterprises of Voronezh;

- allocation, systematization, and determination of significance of factors which determine investment attraction of startup for investor of enterprises with the help of the method of expert evaluations (prioritization), and the coordination of experts' opinions was conducted on the basis of calculation of dispersive coefficient Kendall concordance;

- desk study, including analysis of secondary data (Analytical database on small innovational enterprises and startups of Voronezh) for 2014.

The survey included directors of small enterprise and innovators. This choice was determined by the fact that this very category is the direct generator of new ideas, innovations, and, as a rule, personally solves most of the problems of business and implementation of project tasks. It is determined that significant part of small innovational enterprises (78\%) is created within universities (Fig.1).
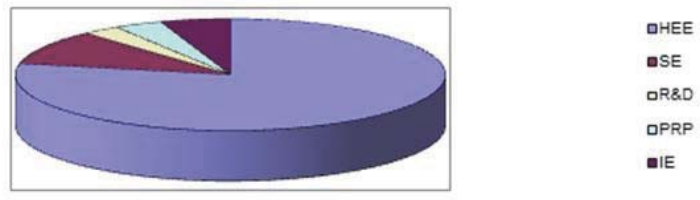

Figure 1. Diagram of distribution of startup projects (novations) as to their belonging (HEE - higher educational establishments, SE - small enterprises, R\&D - R\&D establishments, IE - individual entrepreneurs) 
The individual projects' share in the total quantity of startups projects is $6 \%$.

\section{Results}

Within the concept of creation of specialized electronic resource - investment and innovational electronic platform of cooperation of small innovational business and investors - the scientific and methodological instrumentarium of managing E-platform, its organizational structure, and perspective directions of its development are substantiated. Specialized informational Internet source - electronic investment platform of startups (EIPS) is aimed for investors and startups and is created for the purpose of organization of effective cooperation between them, increasing the accessibility of capital fir beginning Russian businessmen and investment attractiveness of business projects, implemented by legal entities and individuals in the subjects of the RF.

In the process of its work, EIPS should gather and distribute information on innovational projects, small innovational enterprises (startups) among investment society, inform investors on the procedures implemented during fulfillment of investment projects in Voronezh, on investment environment in Voronezh Oblast, and complex of services which could be granted to them.

EIPS should provide unified informational and technological infrastructure in the sphere of innovational business, created through voluntary integration of interested resources of informational provision of innovational and investment business into comprehensive Internet resource, which allows expanding informational and functional capabilities of EIPS through provided services and, therefore, perfecting informational penetration between public authorities, subjects of innovational business, and subjects of investment activities.

Creation of investment and innovational E-platform on the territory of Voronezh Oblast will ensure the following:

- attraction of investments (creation of favorable conditions for attraction of investments into top-priority spheres of economy);

- projects management (documents registering and maintenance);

- Informational maintenance (cooperation with mass media, organization of conferences, seminars, and virtual round tables);

- creation of investment and innovational center for cooperation of scientists, investors, and businessmen;

- Informational provision of investment and innovational policy of the Government of Voronezh Oblast, consulting and expertise of investment projects, organization of their presentations and business meetings with investors for the purpose of attraction of the Russian and foreign investments in the region's economy;

- consolidation of data (databank) on innovational products, technologies, solutions of enterprises, scientific and projects organizations, educational establishments, creative groups, inventors, and developers of scientific and technical products which emerged on the territory of the region.

- selection and expertise of innovations which have large economic effect, preparation of innovational projects offered for implementation.

- organization of constantly working exhibition of innovational projects, organization of exhibition on the territory of the region and beyond it.

- supporting enterprises and organizations of the region in promotion of goods and services, organization of advertising campaigns, publishing leaflets, fliers, informational bulletins, and other promotional materials.

- EIPS structure determines main elements of EIPS, their hierarchy and interconnections. Members and spheres of their cooperation within EIPS are shown in Fig 2. 


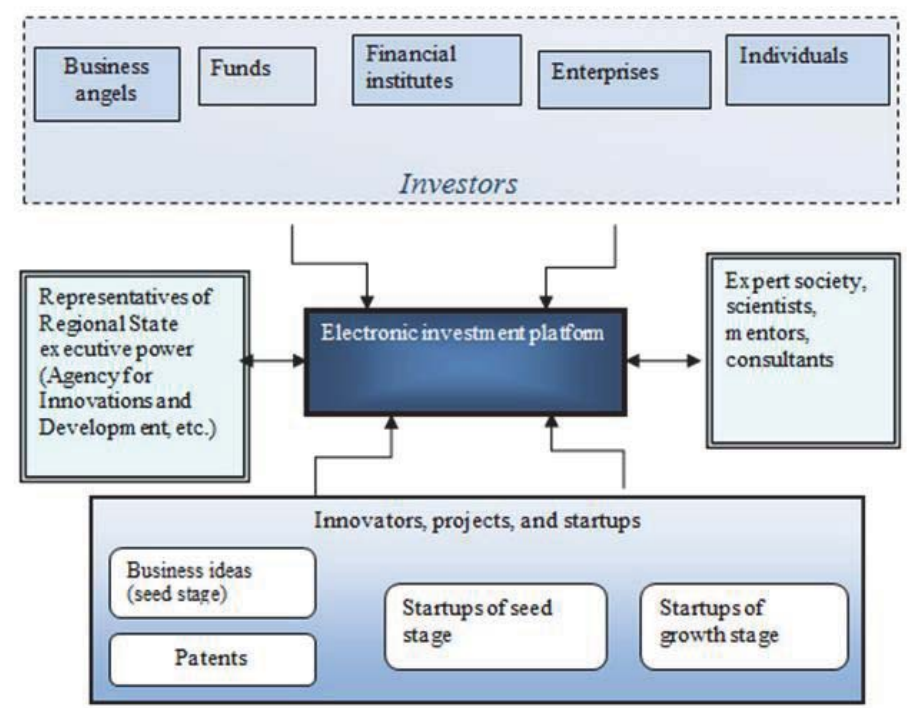

Figure 2. Structure of EIPS

Algorithm of functioning of EIPS in the sphere of cooperation with investors is shown in Table 3.

EIPS structure should correspond to requirements of EIPS architecture and general principles of its building, mentioned above.

Structurally, EIPS should include the several components (sub-systems):

- sub-system of information reflection;

- sub-system of content management;

- sub-system of data storing;

- sub-system of exchange of data between startups, investors (users) and administrator (content administrator, forms operator, expert, moderator).

Given that residents of investment platform will be presented, one the one hand, by perspective projects of startups in various spheres of economy, and, on the other hand, investors, interested in investing capital into such organizations, functioning of electronic investment platform of Voronezh Oblast should be viewed in two aspects:

- cooperation of EIPS with investors;

- cooperation with startups. Within the developed concept, the tasks of EIPS could be the following:

- determining beginning perspective companies (projects), which have a high level of investment attractiveness and informational openness;

- formation of long-term potential basis of emitents;

- preparation of young companies for entering organized market;

- teaching Russian businessmen the investment capital attraction skills;

- formation of wide investor base for the market of beginning companies. 


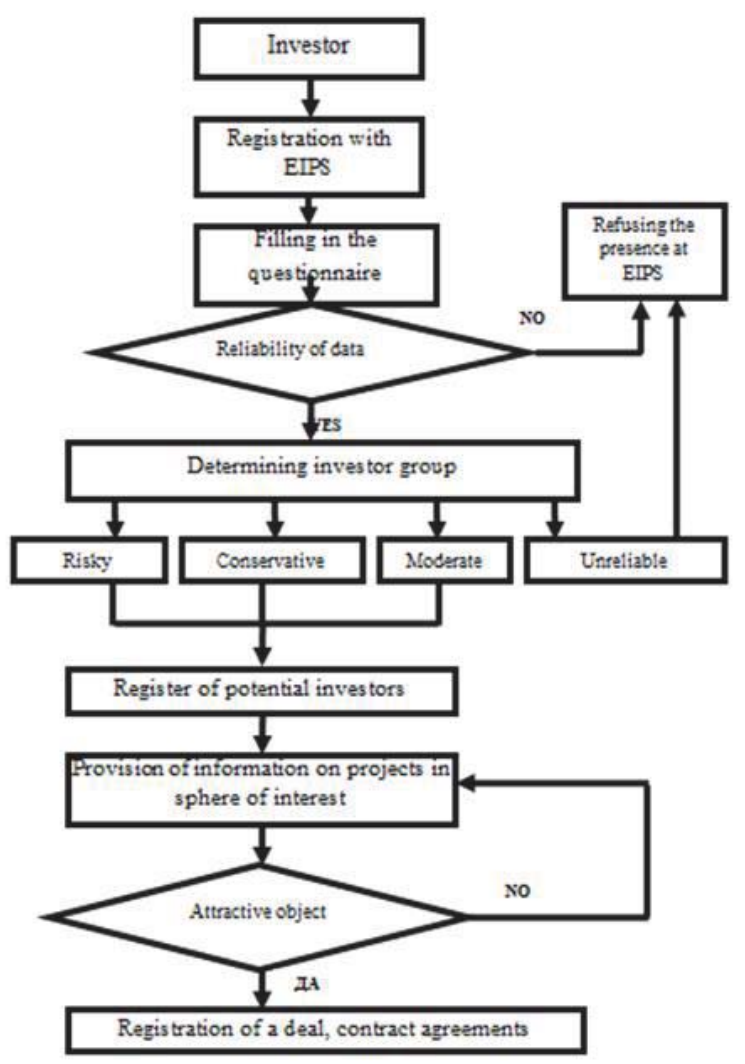

Figure 3. Algorithm of functioning of EIPS in the sphere of cooperation with investors

Investor goes through registration with EIPS, fills in a questionnaire of a set form, and, if the data provided by him is true, he is assigned to one of the group of investors: risky, conservative, moderate, or unreliable.

Taking into consideration the fact that processing and analysis of the questionnaire includes the study of information on enterprise and interesting projects, which may have confidential character, the director of expertise and members of expert groups take obligations for observation of confidentiality and sign the corresponding Agreement.

If investor provides unreliable information or is assigned to the group of the unreliable, he will be refused the presence at EIPS. Risky, conservative, and moderate investors are included into the register of potential investors.

Only after investor's inclusion into this register, the electronic investment platform of startups provides information regarding the projects in the states sphere of interest. Then, investor independently, or with the help of project manager, chooses the project that is attractive for him. relations.

If the project conforms to all requirements of investor, the EIPS deal is made, and attorney registers contract

Algorithm of functioning of EIPS in the sphere of cooperation with startups is shown in Fig. 4. Registration on Platform as a startup is performed after filling in the questionnaire and successful registration. The questionnaire allows beginning businessman to participate in the work of investment platform.

In case of provision of true data, the completed questionnaires form the bank of investments cards of startups and novations.

Informational card of startup contains the data necessary for preliminary expert evaluation of the level of investment attractiveness of startup.

Selection of enterprises for analysis and evaluation of possibility of placing startups at Internet portal is conducted by the department of preliminary expertise of EIPS in concurrence with owner and management of enterprises. If startup 
provided false data in questionnaire or preliminary expertise gave negative decision as to the project, the beginning businessman would be refused the presence at EIPS.

As a result of positive result of preliminary expertise, the catalogue of startups is formed and one of the following decisions is made (stage of provision of services for training, consultations, and preparation of documents).

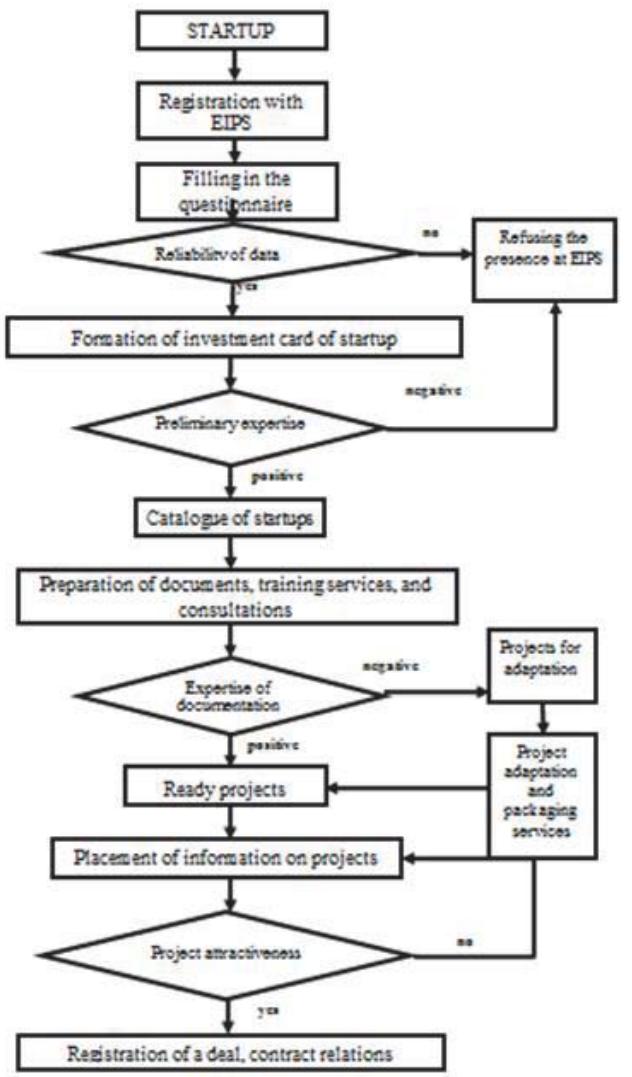

Figure 4. Algorithm of EIPS functioning in the sphere of cooperation with startups

Then, information on ready projects is placed on EIPS and presented to potential investors. At this stage, investors pick up projects which will receive investments.

The projects that were chosen by investors proceed to the final processing according to criteria applied to final investor (stage of contract relations and deal registration).

Operative management of EIPS is implemented according to the scheme, presented in Fig. 5.

According to the shown figure, operative management at EIPS involves the current activities of the Platform within its cooperation with investors and startups, as well as its preservation in working condition.

In this case, management of activities of EIPS is conducted on the following directions:

- provision of services for training, consultations, and holding conferences;

- organization of preliminary expertise and ones held by expert society;

- provision of services for packaging and adaptation of project; in this case, there could be complex support for the project from project manager, coach, mentor, attorney, accountant, etc.;

- conduct of contract relations and making deals between investors and startups. Main emphasis in operative work of EIPS will be made on preparing startups for investing and further entering the public market. For the purpose of operative management of EIPS and control over its state, the following 
algorithms are developed:

- support for E-source in working condition;

- operative management of EIPS;

- tactical management;

- strategic management.

After solving technical and legal issues of creation of electronic investment platform for startups, the Managing Company should do the following:

- prepare the platform for placement of EIPS components (allocate premises which conform to the requirements to placement of EIPS components, organize communication channels, and provide the premises with necessary furniture and equipment);

- provide the functioning of the Platform with highly-qualified specialists not only in the sphere of administration informational systems and data transition networks, but also in marketing, legal, and economic spheres;

- specify budget for creation and functioning of EIPS (changes could be related to rates of inflation, changes in the labor market, etc.);

- determine hardware and software provision of the Platform components and perform its connection to communication channels.

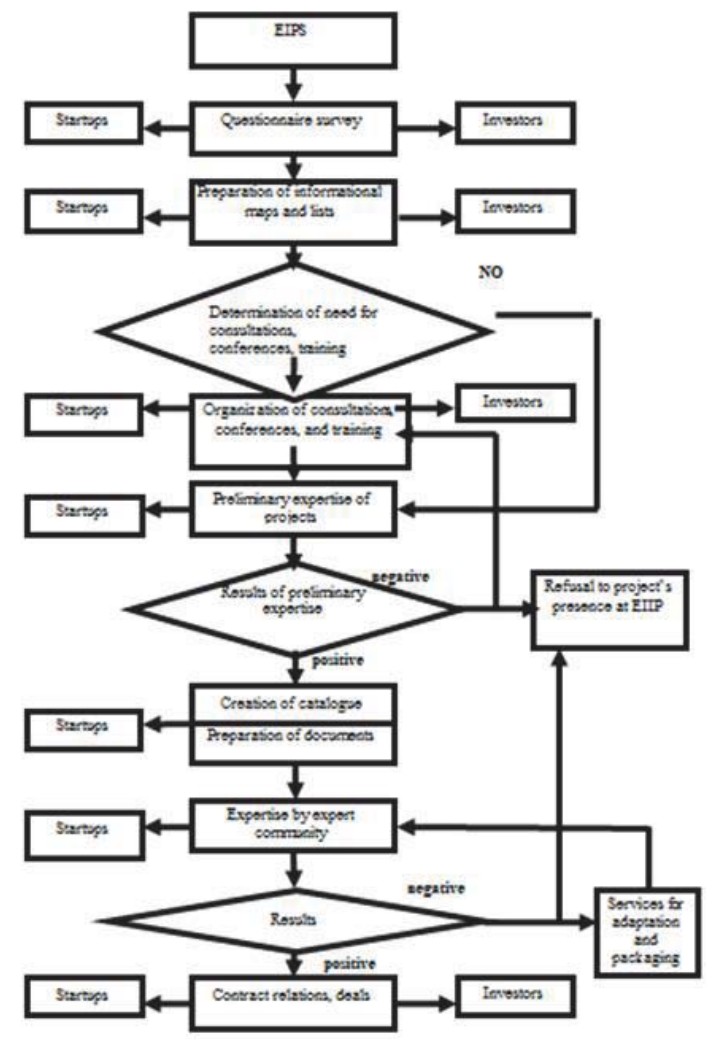

Figure 5. Algorithm of operative management of EIPS for coordination with investors and startups Preparation of EIPS for launch includes:

1. Testing of EIPS components separately and in cooperation; provision of their normal operation.

2. The body, authorized for maintaining the Register and Portal, should receive the corresponding operating instructions. 
3. Persons responsible for functioning of corresponding components of EIPS should be appointed with prepared existing official instructions; they should be trained to work with components of electronic investment startup platforms.

4. Preparation of technological platforms, setting up of hardware and software of EIPS components, or their modernization.

After acceptance inspections of electronic investment platform of startups, it should be put into operation (launch of EIPS).

\section{Discussion}

According to the research of the World Bank "Doing business in Russia 2013", Russia holds112 $2^{\text {th }}$ position of 155 countries in the ranking of countries as to the level of favorability of conditions for doing business: it is ranked new Egypt, Nepal, and Salvador [Doing Business - Measuring Business Regulations., 2015]. For the purpose of support of small innovational business and organization of professional search for venture investments and objects for investments, it is necessary to create regional electronic investment and innovational platforms of cooperation of small innovational business and investors. Critical analysis of existing electronic Internet platforms that support cooperation of startups and investors allowed determining the following:

- pros of web-sites that provide cooperation of startups and investors (presence of startups data bases with significant information and investors; possibility of dialogue of startups and investors through blog and society within Internet resource, presence of experts which prove consistency of startups offers, and market relations between portal members) [Gurunyan, 2013];

- cons of web-sites that provide cooperation of startups and investors (lack of expertise of startups of seed stage, lack of data on implemented startup projects, possibility of search in various languages, insufficient data on investors, difficulties with registration and information exchange) [Shustov, 2013];

- capabilities of web-sites that provide cooperation of startups and investors (evaluation of investment project, making investment agreement, development of business, obtaining business education, and advertising);

- threats of web-sites that provide cooperation of startups and investors (increase of the number of rivals and similar services of higher quality, dishonest startups, investors, and organizers of Internet platforms, investment negative appeal of startups projects, informational limitation of portal, ineffective marketing) [Popkova, 2013].

During the research, the conceptual principles of E-platforms formation within support of small innovational business were formulated:

- principle of demonopolization of investors;

- principle of startups competition;

- principle of cooperation;

- principle of freedom of choice of conditions of investment service and its form provision for startups;

- principle of reliability and guarantee for startups for protection of their interests;

- principle of publicity allows platform members to consciously choose partners;

- principle of limitation of functions of experts and investors;

- principle of competence and professionalism of experts.

We performed the forecast of E-resource functioning. The realistic forecast reflected income expected according to the demand for similar services in the market of investments and innovations. It should be noted that expenses in realistic variant are somewhat lower, which is caused by decrease of need for advertising campaigns and saving on office supplies.

Optimistic forecast includes the income level of RUB 13,500,000 by 2019 and point of return in 2017.

At the same time, we think the preferring optimistic view at development of events may lead to reduction of readiness of EIPS and managerial core (accelerator) to oppose negative tendencies - both in internal and external environments.

During preparation of pessimistic forecast, we based on the assumption of minimal income and maximal expenses for functioning of E-resource. 
Table 1. Forecasts of efficiency of EIPS functioning

\begin{tabular}{|l|c|c|c|c|c|}
\hline \multirow{2}{*}{ Indicators } & \multicolumn{5}{|c|}{ Expected value of result for a year, thousand RUB } \\
\cline { 2 - 6 } & 2015 & 2016 & 2017 & 2018 & 2019 \\
\hline Pessimistic forecast of income and expenses & \multicolumn{5}{|l|}{} \\
\hline Income & 160 & 800 & 4,400 & 6,800 & 7,000 \\
\hline Expenses & 5,902 & 5,848 & 6,107 & 6,257 & 6,312 \\
\hline Balance of income and expenses & $-5,742$ & $-5,048$ & $-1,707$ & 543 & 688 \\
\hline Realistic forecast of income and expenses \\
\hline Income & 350 & 1,600 & 5,200 & 7,400 & 9,000 \\
\hline Expenses & 6,000 & 6,000 & 6,200 & 6,300 & 6,800 \\
\hline Balance of income and expenses & $-5,650$ & $-4,400$ & $-1,000$ & 1,000 & 2,200 \\
\hline Optimistic forecast of income and expenses & 480 & 2,400 & 6,600 & 11,100 & 13,500 \\
\hline Income & 6,000 & 6,000 & 6,200 & 6,400 & 7,200 \\
\hline Expenses & $-5,520$ & $-3,600$ & 400 & 4,700 & 6,300 \\
\hline Balance of income and expenses
\end{tabular}

Indicator of EIPS's income is not homogeneous, as it depends on variety of factors (investment conditions in the region, state of sectors, and support for small innovational business), the values of which can significantly change in the future. Expected value of income for each year was obtained by weighing expected values of relevant factors for each of the variants of development of EIPS.

According to minimal average values of calculations, without consideration of additional types of commercial activities of EIPS, the platform will be able to reach self-sufficiency on its fourth year of functioning.

As to created EIPS, the budget effect will be manifested in direct indicators - volume of tax revenues in budgets of various levels from activities of EIPS (in the form of added value tax, income tax, wages tax for EIPS specialists and involved employees), and indirect ones - manifested in tax revenues from entrepreneurial activities of startups and investors. Direct tax revenues are the most predictable (Table 2).

Table 2. Forecasts of budget efficiency of EIPS

\begin{tabular}{|l|c|c|c|c|c|}
\hline \multirow{2}{*}{ Indicators } & \multicolumn{5}{|c|}{ Expected value of effect for a year, thousand RUB } \\
\cline { 2 - 6 } & 2015 & 2016 & 2017 & 2018 & 2019 \\
\hline Pessimistic forecast of tax revenues & - & - & 108 & 133 \\
\hline Income tax & - & - & 810 & 810 & 810 \\
\hline Wages tax & 576 & 666 & - & 200 & 440 \\
\hline Realistic forecast of tax revenues & - & 810 & 810 & 891 \\
\hline Income tax & - & - & & \\
\hline Wages tax & 576 & 666 & 800 & 940 & 1,260 \\
\hline Optimistic forecast of tax revenues & - & - & 891 & 1,053 & 1,215 \\
\hline Income tax & 576 & 666 & & \\
\hline Wages tax & \multicolumn{5}{|l|}{} \\
\hline
\end{tabular}

For the created EIPS, social effect will be formed in the quantity of created jobs directly at the electronic platform and in the quantity of involved experts, marketing experts, consultants, mentors, etc. (Table 3).

Table 3. Forecasts of social effectiveness of EIPS

\begin{tabular}{|l|c|c|c|c|c|}
\hline \multirow{2}{*}{ Indicators } & \multicolumn{5}{|c|}{ Expected value of effect for a year, thousand RUB } \\
\cline { 2 - 6 } & 2015 & 2016 & 2017 & 2018 & 2019 \\
\hline Pessimistic forecast of quantity of the employed at EIPS & 7 & 8 & 10 & 10 & 10 \\
\hline Quantity of EIPS specialists & 0 & 0 & 0 & 6 & 7 \\
\hline Quantity of involved specialists, experts, etc. & 7 & 8 & 10 & 10 & 11 \\
\hline Realistic forecast of quantity of the employed at EIPS & & 7 & 8 & 9 \\
\hline Quantity of EIPS specialists & 7 & & & \\
\hline Quantity of involved specialists, experts, etc. & 7 & 8 & 11 & 13 & 15 \\
\hline Optimistic forecast of quantity of the employed at EIPS & 7 & 3 & 10 & 15 & 20 \\
\hline
\end{tabular}




\section{Conclusion}

We determined that there is a variety of investment platforms of wide access in the Internet, created for the purpose of uniting businessmen and potential investors; however, at the regional level, due to large quantity of scattered informational resources, there is an objective necessity for formation of single web-site with necessary adapted tools which provide effective cooperation of all interested members, including startups and investors. As a result, the concept of EIPS functioning was formed, the main tasks of which are: attraction of investments (creation of infrastructure for attracting investments into perspective projects and sectors of regional and national economy); consolidation of data on new business projects, perspective projects in various resources of economy in single informational and communicational resource; increase of effectiveness of cooperation of businessmen, investors, and experts by means of uniting at one platform according to specific goals and tasks; development of high-quality consultation \& expert support for projects (accompanying project documentation; marketing and financial help); expert selection and preparation of necessary documentation for projects with high socio-economic effect; informational support for investment activities (organization of advertising activities, cooperation with mass media, conduct of congress and exhibition events).

The results of the created investment and innovational electronic platform for cooperation of small innovational business and investors will include, firstly, increase of transparency of cooperation of investors and startups, as well as subjects of infrastructure of support for innovational business due to placement of information on their activities and results of work (formation of the online-monitoring system); secondly, additional economic effect from supporting the sphere of innovational business; thirdly, increase of investment attractiveness of region as a result of more effective work; fourthly, provision of the system of feedback ("first hand" information) and informational support for startups within provision of complex services in the sphere of business education; investments, consulting, which results in the increase of effectiveness of work; fifthly, creation of data bases of innovations, startups, and investors on the basis of integration with already created Internet resources of Voronezh Oblast.

\section{References}

Shevchenko S.A. Role of small companies in the increase of innovativeness of the Russian economy // Creative economy. - 2010. No. 12 (48). - p. 68-72.

Yulenkova I.B. Innovational small business: necessity and mechanism of development // Russian business. - 2008. - No. 2 Issue 2 (106). - p. 124-128.

Morkovina S.S., Drapalyuk M.V., Kolesnichenko E.A., Busarina Y.V., Stepanov Y.N., N.V. Sukhova, Konstantinov A.V., I.V. Ivanova. Development of innovative activities in the region: vectors of cooperation of investors and startups (monograph). Ministry of education and science of the RF. FSBEI HPO "Voronezh State Forestry Engineering Academy" Moskva-Knorus, 2014. 328 p.

Odarenko V.E. Foreign experience of development of venture business in the sphere of informational services/ Modern science, series "Economics and law"/ No. 1, 2011

Goncharova O.Y. Venture financing of small innovational business in Russia: problems and perspectives // Creative economics. — 2009. - No. 2 (26). - p. 103-107.

Nesterenko Y.N. Small innovational business: new approaches to effective development. Monograph. - M.: MPA-Press, 2006

Popkova Elena G. Mechanisms of Support of Export-Oriented Small Enterprises: The Regional Aspect/ Elena G. Popkova, Svetlana S. Morkovina, , Yulia.V.Busarina, Svetlana V. Budkova/ Asian Social Science Vol.10, No. 23, 2014 ISSN 1911-2017 E - ISSN 19112025 Published by Canadian Center of Science and Education

Morkovina S.S. Innovational mechanisms of cooperation of startups and investors in the Internet environment / Morkovina S.S., Stepanova Y.N., Sukhova V.E., Socio-economic phenomena and processes. - Tambov: Tambov State University named after G.R. Derzhavin, No. 12, 2014, p. 168-174

Panyavina E.A. Small innovational business in Voronezh Oblast: state and perspectives. Panyavina E.A., Safonova N.A., Guzeeva O.G. Socio-economic phenomena and processes. 2014. T. 9. No. 11. P. 148-153.

Bezrukova T.L. Optimization of innovational and investment development of enterprises: theoretical and methodological aspect/ Bezrukova T.L., Bezrukov B.A./ Drukerov Bulletin. 2015. No. 2. P. 20-29.

Doing Business - Measuring Business Regulations., 2015 - Режим доступа: http://www.doingbusiness.org.

Gurunyan T.V., Shcherbina O.Y. Evaluation of infrastructure of support in the system of investment and innovational lift for small and medium business // Russian business. - 2013. - No. 24 (246). - p. 166-174.

Shustov A.A. Expertise of innovational project: idea and necessity of implementation // Creative economics. - 2013. - No. 12 (84). p. 61-67. - http://old.creativeconomy.ru/articles/30901/

Marketing strategy of overcoming of lag in development of economic systems / Popkova E.G., Morkovina S.S., Patsyuk E.V., Panyavina E.A., Popov E.V. // World Applied Sciences Journal. - 2013. - Vol. 26, No. 5. - C. 591-595. 